\title{
Instruments for Analysis of Knowledge Management in Operators Companies of Metropolitan Transport Systems
}

\author{
Manoel Agrasso Neto \\ Centro Universitário FACVEST, Lages, Brasil \\ Andre Ricardo Wesendonck, Viviane D’Barsoles Gonçalves Werutzky \\ Universidade Federal de Santa Catarina, Florianópolis, Brasil
}

\begin{abstract}
This research aimed to determine instruments for analysis of knowledge management in operators companies of metropolitan transport systems. How much the goal was an exploratory research, how much the procedure was a literature search, how much as nature was an applied research, and how much as approach was qualitative research? The following instruments were identified and selected: (a) the methodology for the analysis of metropolitan transport systems; (b) the knowledge management maturity model (Siemens); and (c) Documentation and Information Centre. The simulation, using the tools in the knowledge management to analyze the Company Metropolitan of São Paulo-METRO, identified the need for improvements in eight areas and the problems: (1) rethink the knowledge management area; (2) develop new knowledge management policies; (3) define responsibilities in knowledge management area; (4) implement new knowledge management processes; (5) explore new ways and structures of knowledge; (6) consider the internal and external actors in knowledge management actions; (7) expand the dissemination of the collaborative culture; and (8) integrate in the knowledge management area current and future initiatives. The analysis shows that the transposition of the current situation to the desired situation for the company can be obtained with the implementation of an Information and Documentation Centre. The conclusion is that this set of tools allows to characterize, evaluate, and model the knowledge management in this business.
\end{abstract}

Keywords: organizational intelligence, intellectual capital, complex business, organizational strategies

\section{Introduction}

The choice of subject knowledge management in metropolitan systems operating companies of transport for this research took place, on one hand, due to the demand for consultancy in this area, manifested by a company of this sector based in Latin America, and on the other hand, the familiarity of the authors with knowledge management.

According to Quivy and Campenhoudt (1995), the best way to begin a research work is to formulate a project as an initial question, because through this issue, the researcher will try to express as precisely as possible what it seeks to know, elucidate, and understand better. So two research questions were defined: (a)

Manoel Agrasso Neto, Ph.D., Centro Universitário FACVEST, Lages, Brasil.

Andre Ricardo Wesendonck, master student/business administration, Universidade Federal de Santa Catarina, Florianópolis, Brasil.

Viviane D’Barsoles Gonçalves Werutzky, Ph.D. student, Universidade Federal de Santa Catarina, Florianópolis, Brasil.

Correspondence concerning this article should be addressed to Manoel Agrasso Neto, Servidão Rosa Maria das Neves, 48, Ingleses do Rio Vermelho, CEP 88058-780, Florianópolis, Santa Catarina, Brasil. E-mail: agrassoneto@gmail.com. 
What are the characteristics of the operator companies of metropolitan transport systems; (b) what are instruments used for the analysis of knowledge management in this type of business?

They constitute criteria for choosing and organizing readings according to Quivy and Campenhoudt (1995), from the initial question to avoid a large number of texts, choose synthesis of texts at first to then look for texts that have analysis and interpretation, present different approaches to the subject, and pick out the search sites information and texts on the subject.

SCIELO databases and the Internet were defined as sources of information. The search terms were knowledge management and operators companies of metropolitan transport systems. Title and abstract were defined as search fields. A search performed in SCIELO database has not recovered any records. The Internet search recovered numerous articles on operators companies of metropolitan transport systems, but did not characterize this type of business and did not address the subject knowledge management.

Not getting success on the first search attempt was prompted collaboration with the network of relationships in the librarianship area in Mexico and France. The librarian of the Autonomous National University of Mexico-UNAM managed to regain an article about this type of company with legal approach (Hernández-Mendible, 2008). A collaborator of France managed to regain a dissertation with administrative approach. These two documents give reasons showing characterization of this type of business.

The problem is the approach or theoretical approach adopted to address the problem posed by the initial question. Considering the two questions, the first was answered and the second issue involved topic known to those of researchers. The aim of the study is to determine the instruments for analysis of knowledge management in companies' operator metropolitan transport systems.

\section{Methodology for the Analysis of Metropolitan Transit Systems}

Teles (2007) developed a methodology for the analysis of the metropolitan transit system that has its starting points - the recognition of the deficiencies of the market in transit systems. The first stage includes the characterization of the market and items ranging from the types of marketing efforts to the organizational structures of the market and the interrelationship between the actors, among others. This characterization allows the reflection and analysis of performance.

If no problems are detected, the methodology presents two scenarios of resolution: Either a new and more detailed characterization to allow identification of the existing problems is carried out, or if the problem has been detected, authors pass to the stage of the development of the current structure. Framing the metropolitan transit system in its current structure is to allow improvements, in order to meet this same system on the basis of a future strategic vision, so to frame a future structure. At every stage of the methodology, it may be necessary to resume the stage characterization, as a way to detect and relearn points that have not been subject to the necessary reflection (Teles, 2007).

The methodology allows contextualizing the reality of a metropolitan transit system, taking into account the various items that this system implies, rather than to analyze individually and without the necessary and consistent interaction. As there are multiple combinations of themes, it is also possible to obtain a different "photo" for each specific situation. When this characterization through performance indicators is done, an assessment is made in order to detect problems and frame the existing organizational structure. This review will enable improvements in the system and a better future structure (Teles, 2007). 


\section{Maturity Models of the Knowledge Management}

Knowledge Management has always existed within the organizations, namely, voluntarily or involuntarily, in a structured way or not, but to transform it into a competitive advantage you need to implement structured and coordinated knowledge management (Borba, Knoll, \& Todescat, 2013). Understanding the flow of information and knowledge in the organization is essential for continuous improvement in its entirety, but hardly understanding is not feasible to implement the structured process of knowledge management. There is a need to create tools and models to measure the knowledge management in organizations (Borba et al., 2013).

There are different models of maturity, according to the area of application and in which knowledge management to assess their level of maturity can be based. The important thing is to select the model that most apply to the organizational reality so that the results provide information that will help to draw a realistic plan of action and achieve the desired level of maturity, and thus support the strategic objectives of the organization. The maturity models are applied in various fields of work, such as project management, human resource management, software development, and the topic of interest — knowledge management. These maturity models contain levels that represent the maturity of the application area and elements of measurement to determine this level (Costa, Moura, \& Luna, 2014).

The lack of an international organization that regulates the issue of knowledge management and creates standards for defining models and best practices, has led to the practitioners of the generation of the knowledge society, between academics and consultants and develops different maturity models to apply to cases of timely business (Costa et al., 2014). However, despite their levels and features, most of them can be categorized into three types: (a) models of capability maturity: measure the maturity of an organization ability to perform a certain activity; (b) projects maturity models: focus on the degree of analysis and level of maturity of the processes that are running in the development of a project; and (c) maturity models of ability to change: The level of maturity is placed according to the potential and capacity of response that has an organization to adapt to the changes.

For the implementation of the knowledge management in an organization, it is important to first assess its degree of maturity, for that authors have to select the appropriate methodology in accordance with the guidelines and specific needs of the organization; by developing the valuation, authors can group the results by critical areas or processes, according to their importance to the company. In this way, it is obtained as a result of the current state of knowledge management in the company, being the starting point for its implementation. These activities would be repeated in a new improvement cycle to assess the results of the action plans made and how these contributed to the increase in the level of maturity in accordance with the goals defined in the organization (Costa et al., 2014).

According to views of various authors, a maturity model is a conceptual structure composed of well-established processes through which an organization develops in a planned and systematic way, in order to achieve a desired future state. For each step in this evolution, the maturity model recognizes and notes the increasing maturity of the organization (Prado, 2008). To decide which models are suitable to evaluate the maturity of a particular organization, it is necessary to understand the similarities, differences, and limitations. The models investigated arose between 2000 and 2003. The knowledge management maturity model (Infosys) was the first to be published and the knowledge management capability assessment was the last, but it was 
submitted to a review years later, in 2004. After this period, there is no story of experience in the implementation of any of the models. This is possibly due to the fact that the organizations see their intellectual capital as major competitive advantage. Another possible reason is that the knowledge management models in general belong to consulting firms, which possesses a high cost of implementation, which restricts the disclosure of the contents (Costa et al., 2014).

With regard to the levels of maturity, only knowledge management capability assessment considers six levels, having defined the characteristics of level zero. None of the models studied has superimposed levels, i.e., none of the models that officially allows the improvement actions related to a certain level can be applied before any slope of the previous level has been corrected (Costa et al., 2014).

Each model has a valuation approach. In this context, Siemens knowledge management maturity model is the one that has greater scope, working with workshops, questionnaires, and research. When working with the workshops, this model is also considered as the most in need of an expert in the evaluation process. Other models have a unique approach based on a questionnaire and research or, simply, the approach is based on a questionnaire (Costa et al., 2014). Currently the knowledge management maturity model is widely studied and applied in various organizations to measure the knowledge management. This model is the definition of a conceptual framework of five levels of knowledge management that reflects the value given by the organization to key areas related to the knowledge. Each level presents a standard of the knowledge management in the organization that promotes understanding and planning for improvement and alignment with strategic purposes. The model helps organizations assess their progress on the implementation of this management to a more detailed level. It can be described as a structured set of elements that describe the different levels of maturity (Young, 2010).

According to Ehms and Langen (2002), the levels have the following features: (1) "initial" maturity level - processes are not consciously controlled, activities related to the "successful" knowledge are seen as a stroke of luck and not as the result of setting goals and planning; (2) "repeated" maturity level: The organization has recognized the importance of knowledge management activities for its business. Organizational processes are partially described as knowledge management tasks and under individual ideas of "pioneers in knowledge management", there are pilot projects; (3) "defined" maturity level—established and practiced activities that give effective support to knowledge management in separate parts of the organization. These activities are integrated into the work processes from day to day and their relevant technical systems are maintained; (4) managed - is characterized by the existence of strategy and common approach; indicators on the efficiency of knowledge management activities are regularly measured; senior management and middle management support; activities supported by knowledge management systems; and (5) "optimization" maturity level: Measuring instruments are combined with other knowledge management instruments for strategic control. There are challenges that cannot be solved with knowledge management tools established.

Currently, there are several variations of this model of maturity that has been evolving and adapting to new discoveries, always aiming to achieve a more accurate diagnosis of the knowledge management in the organizations. After the evaluation process, an improvement plan that overcomes the limitations found in the organization shall be developed. According to the approach taken by the four models investigated, the plan must be developed from the results obtained with the model application and experience of the evaluator (Costa et al., 2014). 


\section{Documentation and Information Center}

Maybe because it is a "mixed" entity that does not have a theory and a specific method for the treatment of the collection, the Documentation and Information Center is the institution that occupies less space in the literature of different areas that make science information, although often present in businesses, government agencies, labor organizations, social movements, and universities. The area that best took care of them was the librarianship, because it considered them as part of its domain and did this in a specific dimension: organizing and referencing the documents as isolated parts, whatever its nature, and treating their information as data that is broken and rearranged. Authors are opposed to the application of the principles and rules governing librarianship to all this documentation, in the extent that this procedure violates the various features that the collections centers kept and understand them as entities much more complex. The Documentation and Information Center is a mixture of traditional entities, without being identified with any of them. It collects, by purchase, donation, or exchange documents from different sources, single or multiple (in the form of originals or copies), and/or references on a specific area of human activity. These documents and references can be classified as archives, libraries, and/or museum (Tessitore, 2003).

The Documentation and Information Center aims to gather documents and information about the history of the company, including historical objects, text documents, iconographic, audiovisual, digital media, etc. It operates in the areas of document management, historical research, the dissemination of information, and supports various activities of the organization, constantly striving to record history in the time that is being built. This collection allows the Information and Documentation Center to develop their duties in document preservation and research support in the broadest sense: not only to provide the researcher references to the location of the sources of interest, but also to become a hub documentary production featuring of people and entities who work or worked in their field of expertise (Tessitore, 2003).

\section{Relationship Among Instruments}

Understanding the flow of information and knowledge in the organization is essential for continuous improvement in its entirety, but merely the comprehension makes it not feasible to implement a structured process of knowledge management, there is a need of measuring knowledge management in organizations.

Methodology for metropolitan transport systems analysis (Teles, 2007) can facilitate such comprehension, as it allows to contextualize the reality taking into account the various issues that this system implies, rather than individually analyze without the required and consequent inter-relationship. As there are multiple combinations of themes, it is possible to get a "picture" different for each specific situation. The knowledge management maturity model (Siemens) consists of defining a conceptual framework of five levels of knowledge management that reflect the value given by the organization to key areas related to knowledge (Ehms \& Langen, 2002). Each level shows a pattern of knowledge management that promotes understanding and planning for improvement and alignment with strategic objectives. After the evaluation process, an improvement plan that overcomes the limitations in which the organization is located must be developed from the results obtained from the application of the model and the experience of the appraiser. The concept of Documentation and Information Centre, regardless of the improvement plan of the content, can be responsible for the plan, because it is a mix of traditional entities, without identifying with any of them. It brings together different document sources and single or multiple (a form of originals or copies) references on a specific area of human activity. These documents and references can be typified as archives, libraries, and/or museum (Tessitore, 2003). 


\section{How to Use These Instruments}

The set of instruments has the objective to facilitate the work of professionals in the field of knowledge management that operates in the business of metropolitan transport systems, in order to understand this type of business, diagnose problems, establish the current level of maturity and the desired organization, and propose solutions.

Methodology for analysis transports metropolitan systems is easier to understand and analyze this type of business, which, among other characteristics, is a complex legal nature, involves businesses that are not part of your field of business, and has diversity of involved and interested in the business. The Siemens CMMM maturity model facilitates the analysis and positioning of the organization in one of five levels considered by the model and based on its knowledge management practices and enables you to identify the company's current situation and perspectives future. The Documentation and Information Centre is one of the types of documentary conservation organization and is a mix of other entities, without identifying with any of them. Among its objectives are the research, production, and services. His area of specialization and thematic lines is to define its actions and activities, which can be transformed to the extent that the field of knowledge which is attached is transformed, thus changing their perspectives and demands.

These characteristics represent the competence to adapt to diversity of organizational demands, making it useful at all organizational levels of maturity in terms of knowledge management. After the evaluation process, an improvement plan that overcomes the limitations of the organization should be developed from the results obtained by applying on model and evaluator experience.

\section{Research Methods}

As to objective, this is an exploratory research, because it seeks to familiarize with the knowledge management theme in operators companies of metropolitan transport systems; subject is still little known and little explored. As for the procedures, it is a literature search, because quest theoretical references are already analyzed and published in writings and electronic media, in order to identify instruments for analysis of this type of business. It is applied research, because it aims to generate knowledge to identify and select instruments to analyze this type of business. The approach is a qualitative research, because it does not care about numerical representation, but rather to deepen the understanding of knowledge management in operators companies of metropolitan transport systems (Gil, 2008).

\section{Research Steps}

In step 1, two research questions were defined originally: (a) What are the characteristics of the operators companies of metropolitan transport systems; (b) what are instruments used for the analysis of knowledge management in this type of business? In step 2, sources of information SCIELO databases and the Internet were defined. The search terms were knowledge management and operators companies of metropolitan transport systems. Title and abstract were defined as search fields. In step 3, considering that the first two questions, the first was answered and the second issue involved topic known to those of researchers. The aim of the study became to determine the instruments for analysis of knowledge management in companies operator metropolitan transport systems. In step 4, the main concepts were defined: organizational maturity in $\mathrm{v}$ and the center of documentation and information. The main hypothesis was defined: Whatever the level of maturity organization, documentation, and information center can suit their needs. In step 5, three models were selected: 
(a) the methodology for the analysis of metropolitan transport systems (Teles, 2007); (b) the maturity model of knowledge management, Siemens knowledge management maturity model (Ehms \& Langen, 2002); and (c) Documentation and Information Center (Tessitore, 2003). In step 6, three operations have been defined: (a) present the data (aggregate or not) as required by variables involved in the hypotheses and present them, so that the characteristics of such variables will be evidenced by the description; (b) measure the relationships among the variables, from the way these relationships were foreseen by the hypotheses; and (c) compare the observed relations with relations theoretically expected by the hypothesis and measure the distancing between them. In step 7, it resumes the methodological way, presents the results, and puts in evidence perspectives practices.

\section{Model for Checking the Role of Documentation and Information Centre in Knowledge Management}

The "model for checking the role of Documentation and Information Centre in knowledge management" suggests that the dependent variable "knowledge management desirable" is limited or stimulated by an independent variable "limiters factors and/or stimulators of knowledge management" which can be influenced by a mediating variable/intervener "Documentation and Information Centre" able to facilitate and/or consolidate the knowledge management desirable (Figure 1).

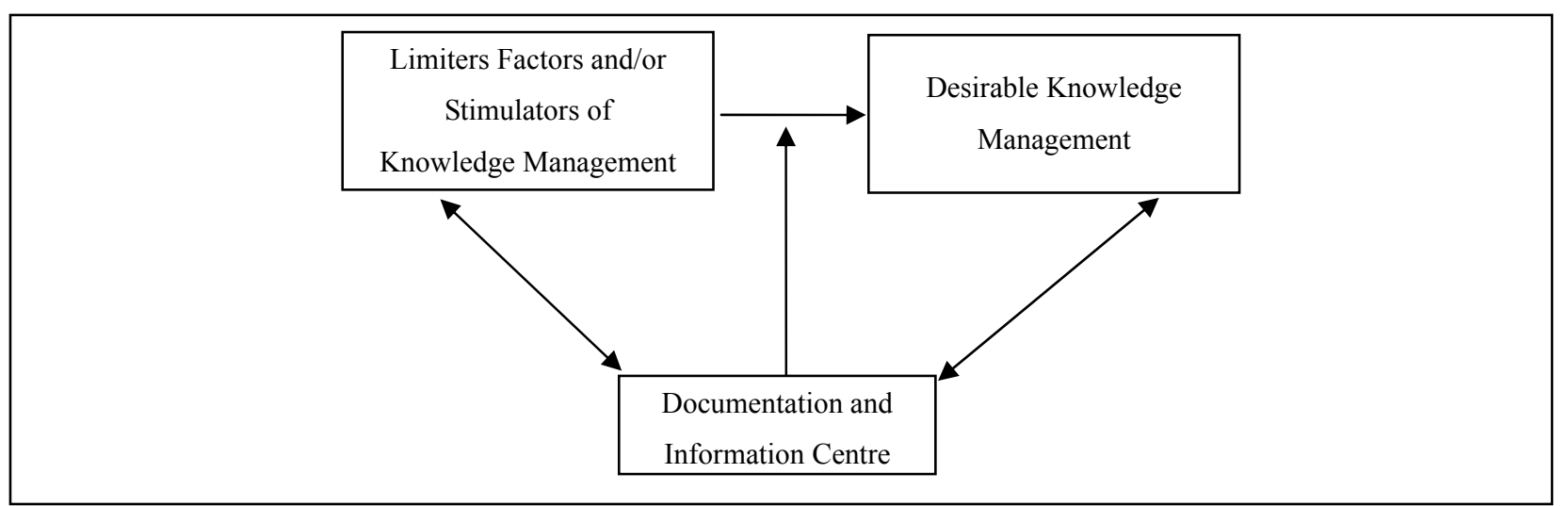

Figure 1. Model for checking the role of Documentation and Information Centre in knowledge management.

The model seeks to highlight the restrictions on the knowledge management and the influence the Documentation and Information Centre may exercise. To this end, this paper sought to data regard to the matters involved in the research object, according to the research variables. In the literature review, it has not been found a model that, by itself, enables the operationalization of the model, thus became necessary combination of various models. The chosen models were: methodology for analysis of metropolitan transport systems (Teles, 2007), Siemens knowledge management maturity model (Ehms and Langen, 2002), and Documentation and Information Centre (Tessitore, 2003). The model for checking the Role of Documentation and Information Centre in knowledge management might facilitate the implementation process, as it allows a more accurate diagnosis of the current situation which enables structure Documentation and Information Centre in accordance with the strategies organizational. The model can be used as an instrument in knowledge management.

\section{Analysis of Knowledge Management in Companies Operators Metropolitan Transport Systems}

The formulation and exploration of the initial question (through reading and data collect), the elaboration of the problem, and the construction of an model of analysis and data gathering resulted in the identification of 
three instruments for analysis of knowledge management in companies operators metropolitan transport system, as described below.

The set of instruments includes: (a) the methodology for the analysis of metropolitan transport systems; (b) the maturity model of knowledge management-Siemens knowledge management maturity model; and (c) Documentation and Information Center. The set of instruments is directed primarily to the personnel responsible for knowledge management in operators companies of metropolitan transport systems. Other recipients who can take advantage of this set of instruments are librarians and consultants who work in this business. With the incorporation of this set of instruments, it is expected that the evaluation of knowledge management in this type of business not be additional or islanded activity but integral part of the formulation of plans and knowledge management policies in operators companies of metropolitan transport systems. The set of instruments comprises a framework for analysis of this type of business, including a maturity model that recognizes and indicates a progressive maturity of the organization in terms of knowledge management, and includes also an entity that brings together traditional knowledge management entities. The set of instruments has three main objectives: It helps to understand, assess/supervise, and plan.

\section{Practical Application}

The simulation of instruments was based on information of the Company of Metropolitan São Paulo-METRO. The documents examined were: Organogram of the Company, Administrative Report 2014 Paper presented at the XV Week metro-railway technology "The Experience of Restoration Maintenance Teams Metro Service São Paulo" (Hirano, Siqueira, \& Barbosa, 2009) and articles.

\section{The Measurements of Knowledge Management in the METRO}

The measurement of levels of maturity CMMM Model (initial, repeated, defined, managed, and optimizing) was performed across eight key areas based on the EFQM (European Foundation for Quality Management), which are as follows: strategy/knowledge goals, support leadership, processes/roles organization, technology infrastructure, knowledge structures/knowledge forms, environment partnerships, people/competence, and collaboration culture. The assessment tool was investigative.

Table 1 shows the results of measurement on the vertical axis which are the levels listed in the model CMMM and the horizontal axis are the areas listed in EFQM. The practices identified in METRO are described and classified following.

Table 1

Knowledge Management Maturity Levels in Metro

\begin{tabular}{|c|c|c|c|c|c|c|c|c|}
\hline $\mathrm{Cmmm}$ model & $\begin{array}{l}\text { Strategy } \\
\text { knowledge } \\
\text { goals }\end{array}$ & $\begin{array}{l}\text { Leadership } \\
\text { support }\end{array}$ & $\begin{array}{l}\text { Processes } \\
\text { roles } \\
\text { organization }\end{array}$ & $\begin{array}{l}\text { Technology } \\
\text { infrastructure }\end{array}$ & $\begin{array}{l}\text { Knowledge } \\
\text { structure } \\
\text { and forms }\end{array}$ & $\begin{array}{l}\text { Environment } \\
\text { partnerships }\end{array}$ & $\begin{array}{l}\text { People } \\
\text { competencies }\end{array}$ & $\begin{array}{l}\text { Collaboration } \\
\text { culture }\end{array}$ \\
\hline \multicolumn{9}{|l|}{ Level 1 initial } \\
\hline Level 2 repeated & & & $\mathrm{X}$ & & $X$ & & $X$ & $X$ \\
\hline Level 3 defined & $X$ & $X$ & & $X$ & & X & & \\
\hline Level 4 managed & & & & & & & & \\
\hline Level 5 optimizing & $\begin{array}{l}\text { Level } \\
\text { desired }\end{array}$ & $\begin{array}{l}\text { Level } \\
\text { desired }\end{array}$ & $\begin{array}{l}\text { Level } \\
\text { desired }\end{array}$ & $\begin{array}{l}\text { Level } \\
\text { desired }\end{array}$ & $\begin{array}{l}\text { Level } \\
\text { desired }\end{array}$ & $\begin{array}{l}\text { Level } \\
\text { desired }\end{array}$ & Level desired & $\begin{array}{l}\text { Level } \\
\text { desired }\end{array}$ \\
\hline
\end{tabular}

The results of the measured areas show that, according to established practice, four areas are situated on level 2, four areas situated on level 3, and the desired level is level 5. They are described below established 
practices for each level.

The "strategy area and knowledge goals" exists as practices established the knowledge retention policy acquired by Metro Company professionals. The practice was defined as level 3 as the only identified practical and therefore a practice isolated. It was observed that the mission of the management services and infrastructure (GSI) is to endow the Metro Company of adequate conditions of building infrastructure and administrative services, preserving its heritage, including the documentary. The mission of the GSI suggests that documentation is not their competence which is not a priority.

The practice identified in the leadership support area and established, as level 3 was the presentation of the work "the experience of the teams of restoring maintenance of the São Paulo Metro Services" (Hirano et al., 2009), which the authors' intention was to pay tribute to the effort and dedication over the course of more than 20 years, of all the professionals involved in this work and knowledge management process.

In processes organization roles area, the practices were defined as level 3, because only the elaboration process of internal training aiming at retaining knowledge acquired can be regarded as defined, others did not.

In the technology infrastructure area, electronic and electromechanical equipment maintenance was identified, thus defined as level 3 .

In the area of knowledge structure and knowledge forms, practices established are the Training Development Process Internal and Corporative University-UNIMETRO, though the UNIMETRO has no legal nature, does not charge for its services, and has no return on assessment practice over investments in corporate education. Thus, it was defined as level 2.

In the area of environment partnerships, agreements to modernize and expand the lines of the São Paulo subway, cultural activities, and social campaigns have been identified, so defined as level 2.

In the area of people competencies, there exists a necessity to create competencies for mastering the increasing volume of information turning them into knowledge, training requirements which no longer meet an appropriate manner and the need to of knowledge management tools for professional improvement, thus defined as level 2.

In the area of collaboration culture, the "Social Network Tool Corporate" known as "next station - knowledge" was identified, designed to stimulate the sharing and dissemination of information and knowledge, facilitating connection and offering space and tools for creating and interchange of ideas and views on general matters and professionals, thus defined as level 2.

An improvement plan that overcomes the limitations found in the organization should be developed, after the evaluation procedure. According to the approach taken by the model knowledge management maturity model, the plan should be developed from the results obtained by applying the model and the evaluator experience.

\section{Plan for Knowledge Management Improvement on the METRO}

The human experience has produced and accumulated a large number of records which constitute document, technically defined as a set of information and its support. The book, magazine article, the medical record, the letter, the poster of a seminar, the video conference, the legislation, the objects used, etc. are documents. To comply with its social, administrative, legal, technical, scientific, cultural, artistic, and/or historical records, it is necessary that the document be preserved, organized, and accessible.

The measurement of maturity levels in knowledge management in the METRO allowed the identification necessity of improvements in eight areas related to knowledge management. The areas are: strategy/knowledge 
goals, support leadership, processes/roles organization, technology infrastructure, knowledge structures/knowledge forms, environment partnerships, people/competence, and collaboration culture.

The needs identified were: (1) rethink the knowledge management area; (2) develop new knowledge management policies; (3) define responsibilities in knowledge management area; (4) implement new knowledge management processes; (5) explore new ways and structures of knowledge; (6) consider the internal and external actors in knowledge management actions; (7) expand the dissemination of the collaborative culture; and (8) integrate in the knowledge management area current and future initiatives.

There are four types of entities that carry out this task: archives, libraries, museums, and documentation and information centers. The Documentation and Information Centre is a mix of other entities, extrapolating their documentary universes. The accumulation of this acquis enables Documentation and Information Center to comply with their duties in document preservation and research support in the broadest sense: not only making it available to the researcher references to the location of the sources of interest, but also becoming one pole of attraction of document production persons and entities that operate or acted in his field of expertise.

The area of expertise Documentation and Information Centre will guide the development of thematic lines, around which there will be given training and the expansion of the acquis and the establishment of programs of action and the definition of activities. However, these lines are not fixed and unchanging. They will undergo a process of transformation as the field of knowledge to which the center is linked turns, changing their perspectives and demands of research, since these changes involve new demands for information.

Table 2 presents the steps for implementation of the Documentation and Information Centre.

Table 2

Steps for Implementation of Documentation and Information Centre

\begin{tabular}{|l|l|}
\hline $\begin{array}{l}\text { Steps for implementation of the } \\
\text { Documentation and Information Centre }\end{array}$ & Objectives \\
\hline 1 - Definition area of specialization & $\begin{array}{l}\text { The initial and fundamental step in realizing the Center is their official creation, through } \\
\text { the appropriate formal instruments which involve a name, nature, purpose, objectives, } \\
\text { subordination, internal structure, and functions; these instruments are approved by the } \\
\text { relevant bodies. }\end{array}$ \\
\hline 2 - Organizational structure & $\begin{array}{l}\text { It should reflect its functions, which may be more or less extensive, depending on the } \\
\text { entity's objectives. }\end{array}$ \\
\hline 3 - Functions & $\begin{array}{l}\text { The Center can be subdivided into technical areas, by function rather than by type of } \\
\text { collection and an administrative area. In complex organizations, they can also be } \\
\text { subdivided according to the nature of the acquis. }\end{array}$ \\
\hline 4 - Humans resources & $\begin{array}{l}\text { The most modern infrastructure, however, does not give life to the center, if there is no } \\
\text { competence technical staff to operate it, which will be responsible for carrying out the } \\
\text { activities planned in the implementation stages, but also of materializing routine } \\
\text { services, continuity of work and its future expansion. }\end{array}$ \\
\hline
\end{tabular}

The Documentation and Information Centre can be seen as a back office area that adds safety, considering the present, past, and future, giving answers to the demands; serves the front office which adds value. In complex organizations, the back office mission is to add security in terms of the content consistency of information systems and structure front office service information an appropriate manner by guiding the production of information.

\section{Conclusions}

With the objective of determining instruments for analysis of knowledge management in operators metropolitan transportation systems business, a literature search was carried out, with exploratory objective of 
an applied nature and qualitative approach. The results were as the followings:

(1) Three instruments were determined for analysis of knowledge management in operators companies of metropolitan transport systems: (a) the methodology for the analysis of metropolitan transport systems (Teles, 2007); (b) the maturity model—Siemens knowledge management maturity model (Ehms \& Langen, 2002); and (c) Documentation and Information Centre (Tessitore, 2003).

(2) The simulation uses the tools in the knowledge management to analyze the Company Metropolitan of São Paulo-METRO. The need for improvements in eight areas and the problems were identified: (a) rethink the knowledge management area; (b) develop new knowledge management policies; (c) define responsibilities in knowledge management area; (d) implement new knowledge management processes; (e) explore new ways and structures of knowledge; (f) consider the internal and external actors in knowledge management actions; (g) expand the dissemination of the collaborative culture; and (h) integrate in the knowledge management area current and future initiatives.

(3) The analysis shows that the transposition of the current situation to the desired situation for the company can be obtained with the implementation of an Information and Documentation Centre. The role of the Documentation and Information Centre is to provide security to front office.

(4) The conclusion is that this set of instruments allows to characterize, evaluate, and model the knowledge management in this business.

Future research should: (a) characterize in more detail this type of business; (b) identify practices of knowledge management implementation in this business; and (c) identify best knowledge management practices in this business.

\section{References}

Borba, F. R., Knoll, E. C., \& Todescat, M. (2013). Diagnóstico dos Niveis de Maturidade em Gestão do Conhecimento: Centro de empreendimento inovador da Fundação CERTI. Navus—Revista de Gestão e Tecnologia. Florianópolis, 3(2), 163-176.

Costa, C. P., Moura, H. P., \& Luna, A. J. H. (2014). Modelos de Maturidade de Gestão do Conhecimento: Uma Análise Comparativa. Retrieved from http://www.ufpi.br/subsiteFiles/ercemapi/arquivos/files/artigos/pos/pg9.pdf

Ehms, K., \& Langen, M. (2002). Holistic development of knowledge management with KMMM. Retrieved from $\mathrm{http} / / / w w w . k m m m . o r g / o b j e c t s / k m m m \_a r t i c l e \_s i e m e n s \_2002 . p d f$

Gil, A. C. (2008). Como elaborar projetos de pesquisa (5th ed.). São Paulo: Atlas.

Hernández-Mendible, V. R. (2008). La Regulación del Sistema de Transporte Metropolitano. Ciudad de México: UNAM. Retrieved from www.juridicas.unam.mx

Hirano, A., Siqueira, L. C. H., \& Barbosa, S. (2009). Gestão do Conhecimento-A Experiência das Equipes de Manutenção de Restabelecimento de Serviços do Metrô de São Paulo. Proceedings from 15 STM 09: 15 Semana Tecnológica Metrôferroviária. São Paulo, SP: AEAMESP.

Prado, D. (2008). Maturidade em Gerenciamento de Projetos (INDG Tecnologia e Serviços, Minas Gerais, Brasil).

Quivy, R., \& Campenhoudt, L. V. (1995). Manuel de recherche en sciences sociales. Paris: Dunod.

Teles, M. F. C. S. (2007). Metodologia de Análise de Um Sistema de Transporte Metropolitano: o caso da Autoridade Metropolitana de Transportes do Porto (AMTP) (Dissertação (Mestrado), Faculdade de Engenharia da Universidade do Porto).

Tessitore, V. (2003). Como Implantar Centros de Documentação. São Paulo: Arquivo do Estado, Imprensa Oficial.

Young, R. (2010). Knowledge management tools and techniques manual. Retrieved from $\mathrm{http} / / / w w w . a p o-t o k y o . o r g /$ publications/files/ind-43-km_tt-2010.pdf 